\title{
Análise quantitativa e qualitativa dos resíduos de construção e demolição gerados em Belo Horizonte/MG
}

\author{
Quantitative and qualitative analysis of the construction and demolition waste \\ generated in Belo Horizonte/MG
}

Sofia Araújo Lima Bessa[a] $\odot$, Tiago Augusto Gonçalves Mello[a], Karen Katleen Lourenço[a]

[a] Universidade Federal de Minas Gerais (UFMG), Escola de Arquitetura, Belo Horizonte, MG, Brasil

Como citar: Bessa, S. A. L., Mello, T. A. G., \& Lourenço, K. K. (2019). Análise quantitativa e qualitativa dos resíduos de construção e demolição gerados em Belo Horizonte. urbe. Revista Brasileira de Gestão Urbana, 11, e20180099. https://doi.org/10.1590/2175-3369.011.e20180099

\section{Resumo}

A construção civil é um dos setores econômicos que mais impactam o meio ambiente. 0 volume de resíduos de construção e demolição (RCD) gerados nas cidades e a sua disposição inadequada são fatores que potencializam a degradação ambiental. 0 objetivo do presente trabalho foi realizar uma análise quantitativa e qualitativa da produção dos RCD em Belo Horizonte, MG. Como parte da análise qualitativa, realizou-se um levantamento do atual estado da gestão e do gerenciamento dos RCD gerados na cidade com vistas a entender a viabilidade do uso dos RCD reciclados como insumo na construção civil da região metropolitana de Belo Horizonte (RMBH). Após essa etapa, foi realizada coleta e caracterização dos RCD na estação de reciclagem de entulho (ERE/ SLU), situada na BR040. Utilizou-se o método de amostragem de acordo com a norma pertinente. Por meio da análise gravimétrica, observou-se que 95,5\% do total de RCD produzidos é do tipo A, o que indica um grande potencial técnico e econômico de reaproveitamento diretamente na construção civil. Os resultados apontam, portanto, a necessidade de diretrizes para a aplicação destes resíduos de volta na construção civil e para a criação de políticas de educação ambiental.

Palavras-chave: Resíduos de construção e demolição. Gestão de resíduos. Reaproveitamento. Construção civil.

\begin{abstract}
Civil construction is one of the economic sectors that most impact the environment. The volume of construction and demolition waste (CDW) generated in cities and their inadequate disposal is factors that potentiate environmental degradation. The objective of the present work was to perform a quantitative and qualitative analysis of the production of CDW in Belo Horizonte, MG. As part of the qualitative analysis, a survey was carried out of the current state of management of CDW in the city with a view to understanding the feasibility of using CDW recycled as input in the construction industry of the metropolitan area of Belo Horizonte. After this step, the CDW sample was collected and characterized at the rubble recycling station located at BR040. The sampling method was used according to related norms. Through the gravimetric analysis, it was observed that 95.5\% of the total CDW produced is type A, which
\end{abstract}

SALB é professora adjunta, e-mail: sofiabessa@ufmg.br

TAGM é graduando em Arquitetura e Urbanismo, e-mail: tiagoaugustogm@gmail.com

KKL é arquiteta e urbanista, e-mail: kkl.arquitetura@gmail.com 
indicates a great technical and economic potential for reuse directly in the construction industry. Therefore, the results indicated the need for guidelines for the application of these residues back in the civil construction and for the creation of environmental education policies.

Keywords: Construction and demolition waste. Waste management. Reuse. Civil construction.

\section{Introdução}

Nas últimas décadas, o padrão de geração e as características dos resíduos sólidos têm experimentado uma modificação substancial. De maneira geral, nos centros urbanos, há uma tendência crescente em gerar cada vez maiores quantidades de resíduos sólidos, como também de ocorrer uma modificação significativa na sua composição, com predomínio de materiais não biodegradáveis (Belo Horizonte, 2015). Essa crescente produção de resíduos também afeta os pequenos municípios no que diz respeito aos impactos ambientais, sociais e/ou econômicos, uma vez que encontram entraves quanto à sua destinação, principalmente econômicos (Monteiro et al., 2017).

Segundo o panorama da situação dos resíduos sólidos no Brasil, elaborado pela Associação Brasileira de Empresas de Limpeza Pública e Resíduos Especiais - ABRELPE, do ano de 2017, em torno de 62\% de todo o resíduo sólido gerado no Brasil teve como origem as atividades de construção e de demolição, o que equivale a, aproximadamente, 45 milhões de toneladas de resíduos de construção e demolição (RCD) gerados por ano num total de 71,6 milhões de toneladas de resíduos sólidos urbanos. Os dados apontam um total de $123 \mathrm{mil}$ t/dia de RCD, sendo cerca de $64 \mathrm{mil}$ t/dia coletadas apenas na região Sudeste (51,75\%) (ABRELPE, 2017).

Todavia, a quantidade real de resíduos gerados pode ser ainda maior, visto que esses valores se referem apenas aos materiais coletados legalmente ou destinados aos coletores públicos. Em Belo Horizonte, nessa situação, em torno de 230 toneladas de resíduo são coletadas por dia (Belo Horizonte, 2018a). Há uma tendência ao agravamento do quadro dada a continuidade e perpetuação das lógicas de geração e incorreta disposição.

Em contrapartida, e de acordo com o último Anuário Mineral Brasileiro publicado (ANM, 2010), o total de areia natural extraído foi de 255 milhões de toneladas anuais com um total de 68\% utilizado na construção civil. A extração da areia tem um custo ambiental (por modificação na paisagem durante a extração) e econômico (pelos custos de transporte envolvidos) muito altos, que poderiam ser minimizados, em parte, com a utilização dos RCD gerados localmente.

Para comprovar a destinação ambientalmente adequada dos resíduos sólidos, uma instituição precisa elaborar o seu plano de gerenciamento. Por sua vez, este conceito se afina às medidas adotadas no processo de coleta, transporte e disposição final com o fim de lhes dar uma destinação sustentável. Ainda assim, a gestão adequada precisa estar organizada com iniciativas concretas da administração pública com vias a estabelecer diretrizes adequadas de manejo dos resíduos em sua totalidade, com ações que envolvam desde a educação ambiental, a coleta seletiva e a reutilização desses resíduos.

A cidade de Belo Horizonte conta com uma estrutura de referência nacional em relação à gestão e ao gerenciamento dos RCD gerados, porém grande parte desse montante ainda é destinado ao aterro sanitário, com uma parcela ainda descartada clandestinamente, sem uma efetiva ação da municipalidade.

Nesse contexto, o objetivo deste trabalho foi realizar uma análise quantitativa e qualitativa da geração dos RCD em Belo Horizonte com vistas à possibilidade de uso desse resíduo como parte de uma economia circular na cidade que inclua as atividades de construção civil como agente gerador e receptor desse resíduo. Como parte da análise qualitativa, realizou-se um levantamento do atual estado da gestão e do gerenciamento dos RCD na cidade e, além disso, a partir do panorama alcançado, buscou-se entender a viabilidade do uso dos RCD reciclados como insumo na construção civil. 


\section{Referencial teórico}

Desde 2002, diretrizes, critérios e procedimentos para a gestão de RCD estão disciplinados pela resolução no 307 do Conselho Nacional do Meio Ambiente (Brasil, 2002), órgão consultivo e deliberativo do Sistema Nacional do Meio Ambiente (Sisnama). Essa legislação se tornou norteadora de outras mais recentes, como a Política Nacional de Resíduos Sólidos (Brasil, 2010) e a Lei 10.522 (Belo Horizonte, 2012), que incorporaram diretrizes gerais das anteriores, mas que também inovaram, por exemplo, com a determinação de substituição dos lixões por aterros sanitários.

Essa resolução define, também, a classificação dos resíduos - Resolução do Conama no 307 (Brasil, 2002) e no 431 (Brasil, 2011) - em Resíduos Classe A, B, C ou D, que inclui:

Resíduos classe A: são os resíduos reutilizáveis ou recicláveis como agregados, tais como: a) de construção, demolição, reformas e reparos de pavimentação e de outras obras de infraestrutura, inclusive solos provenientes de terraplanagem; b) de construção, demolição, reformas e reparos de edificações: componentes cerâmicos (tijolos, blocos, telhas, placas de revestimento etc.), argamassa e concreto; c) de processo de fabricação e/ou demolição de peças pré-moldadas em concreto (blocos, tubos, meio-fios etc.) produzidas nos canteiros de obras; Resíduos classe B: são os resíduos recicláveis para outras destinações, tais como plásticos, papel, papelão, metais, vidros, madeiras, embalagens vazias de tintas imobiliárias e gesso; Resíduos classe C: são os resíduos para os quais não foram desenvolvidas tecnologias ou aplicações economicamente viáveis que permitam a sua reciclagem ou recuperação; Resíduos classe D: são resíduos perigosos oriundos do processo de construção, tais como tintas, solventes, óleos e outros ou aqueles contaminados ou prejudiciais à saúde oriundos de demolições, reformas e reparos de clínicas radiológicas, instalações industriais e outros, bem como telhas e demais objetos e materiais que contenham amianto ou outros produtos nocivos à saúde (Brasil, 2002).

É também dessa legislação que se extrai o termo gestão, vinculado ao conceito de gestão integrada de resíduos sólidos, definido como o "[...] conjunto de ações voltadas para a busca de soluções para os resíduos sólidos, de forma a considerar as dimensões política, econômica, ambiental, cultural e social, com controle social e sob a premissa do desenvolvimento sustentável [...]" (Brasil, 2002).

Este conceito, assim, aponta para as iniciativas e as proposições de soluções para os problemas ligados aos resíduos.

No Brasil, o gerenciamento de resíduos sólidos é definido pela Política Nacional de Resíduos Sólidos, art. $3^{\circ}$, inciso X:

Gerenciamento de Resíduos Sólidos: conjunto de ações exercidas, direta ou indiretamente, nas etapas de coleta, transporte, transbordo, tratamento e destinação final ambientalmente adequada dos resíduos sólidos e disposição final ambientalmente adequada dos rejeitos, de acordo com plano municipal de gestão integrada de resíduos sólidos ou com plano de gerenciamento de resíduos sólidos, exigidos na forma desta Lei [...] (Brasil, 2010).

Em outra classificação, pela NBR 10004 (ABNT, 2004d), os RCD não constam especificamente no Anexo H (Codificação de alguns resíduos classificados como resíduos perigosos) mas podem ser enquadrados como Outros resíduos não perigosos, pois não contêm substâncias listadas nos Anexos A, B, C, D ou E.

A reutilização e a reciclagem de materiais apresentam-se como eficientes alternativas para minimizar os impactos da geração e do acúmulo de RCD ao impulsionar a sua valorização econômica pela indústria da construção civil. No Brasil, vem crescendo o número de empresas, entre outros segmentos do setor, que passaram a incorporar aos canteiros soluções projetuais com vistas à sustentabilidade, através do monitoramento do consumo de recursos e de novas tecnologias para reciclagem e reutilização dos diversos tipos de resíduos gerados (Baptista \& Romanel, 2013).

É de fundamental importância que a construção civil brasileira passe, como um todo, por revisão no modus operandi para que a lógica do desperdício dos materiais de construção ao longo das obras seja 
diminuída. Isso é uma visão macro da sustentabilidade do setor, uma vez que a maior parte dos materiais usados (cerâmicas, tijolos, telhas, cimento, cal, etc.) são provenientes de matérias-primas naturais, diretamente, ou foram obtidos pelo processamento destas.

Como substitutos dessa matéria-prima convencional (agregados), os RCD reciclados/processados podem vir a colaborar para diminuir o custo direto nas obras (Tam et al., 2018) e possibilitar, também, a diminuição de problemas decorrentes do acúmulo e deposição de resíduos em áreas inadequadas.

A busca pela eficiência, com vistas à diminuição do consumo de recursos naturais e o consequente impacto ambiental, incentiva um crescente mercado de produtos com viés sustentável. Os benefícios de sua reutilização diminuem a possibilidade de deposição de resíduos em locais inadequados, bem como a necessidade de extração de matéria-prima em jazidas, nem sempre fiscalizadas do ponto de vista ambiental (Baptista \& Romanel, 2013).

Dessa forma, de um lado, tem-se a indústria da construção civil que extrai de um lado e descarta de outro, mantendo o ciclo aberto, e com o agravante de desperdiçar muitos recursos materiais durante as obras por ineficiência operacional (Brasileiro \& Matos, 2015).

A Construção Civil apresenta-se como uma das mais importantes atividades para o desenvolvimento econômico e social, mas, por outro lado, é a maior geradora de impactos ambientais pelo elevado consumo de matérias-primas, entre $20 \%$ e $50 \%$ dos recursos naturais de todo o planeta (Brasileiro \& Matos, 2015). Grande parte dos resíduos gerados nos canteiros de obras brasileiros é composta por restos de argamassas, tijolo, alvenaria, concreto, cerâmica, gesso, madeira, metais, etc., que são descartados em aterros por ineficiência no sistema de gerenciamento, por falta de investimento de mercado em seus produtos (Duran et al., 2006).

Na Espanha, 25-30\% dos resíduos sólidos gerados são provenientes de atividades de construção e de demolição, mas, ainda assim, apenas 15\% dos RCD são reaproveitados, ao contrário de outros países europeus cuja média de reutilização dos RCD chega a 70\% (Rodríguez et al., 2015). No Canadá, 27\% dos resíduos dispostos em aterro sanitário são RCD, o que denota uma falha, ainda, na política de reaproveitamento desses resíduos (Yeheyis et al., 2013). No contexto canadense, a madeira corresponde a $50 \%$ dos resíduos de demolição e a $30 \%$ dos resíduos de construção, uma realidade diferente da brasileira, na qual grande parte dos RCD corresponde a resíduos classe A (Brasil, 2002).

Após o recebimento, os RCD brasileiros possuem uma densidade média de 1,20 ton $/ \mathrm{m}^{3}$ (IBAM, 2001). Scremin et al. (2014) obtiveram o valor de 1,28 ton $/ \mathrm{m}^{3}$ para os resíduos de Pelotas, RS, com $88 \%$ dos RCD concentrados na classe A. Oliveira et al. (2011) atestaram que, na cidade de Fortaleza, $65 \%$ dos RCD são constituídos por resíduos minerais (classe A), sendo a maior parte constituída por argamassas. Esses dados confirmam a cultura construtiva brasileira, na qual as maiores perdas ocorrem nas fases de concretagem, alvenaria, emboço/reboco e revestimento, em que os grandes insumos utilizados são esses que aparecem em grandes quantidades nos resíduos de construção e demolição (Oliveira et al., 2011).

A taxa de geração da cidade de Fortaleza ficou em 0,12 toneladas de RCD/habitante/ano. Os autores enfatizaram que esse valor abaixo da média nacional é devido a não detecção, neste estudo, dos resíduos dos pequenos geradores, uma vez que se avaliou somente o resíduo transportado por empresas, que usualmente atendem somente às construtoras. Habitualmente os resíduos dos pequenos geradores são depositados irregularmente em locais não licenciados (Oliveira et al., 2011).

A parte inerte (mineral) dos RCD é considerada a menos poluente para o meio ambiente, mas deve ter prioridade de reciclagem, segundo o European Union Waste Strategy. Ainda assim, há alguns componentes potencialmente perigosos que podem estar associados a esses resíduos (asbestos, aditivos, etc.) que podem, sim, prejudicar o meio ambiente se não forem corretamente dispostos (Wu et al., 2014).

0 uso dos RCD como matéria-prima é a peça-chave que fecha o ciclo e promove, diretamente, uma sustentabilidade ao sistema. Pontua-se que a viabilidade econômica pode ocorrer, por exemplo, quando o custo de implantação e de manutenção do aterro para os RCD excede o custo de trazer o mesmo resíduo para o centro de reciclagem e o custo de usar agregados primários excede (e muito) o custo de uso de agregados reciclados. Além disso, os centros de reciclagem se beneficiam de produção em escala, o que pode resultar em uma diminuição nos custos de reciclagem (Duran et al., 2006; Tam et al., 2018). 
As normas NBR 15115 (ABNT, 2004b) e 15116 (ABNT, 2004c) já possuem diretrizes gerais para o uso de agregados reciclados de resíduos sólidos da construção civil.

De acordo com Bernardes et al. (2008), os estudos já realizados, de forma geral, indicaram que a realização de um diagnóstico local se mostra como primeiro passo para o gerenciamento eficaz dos RCD. A identificação dos aspectos referentes a esses resíduos tais como origem, taxa de geração, agentes envolvidos na geração e coleta, destinação final, entre outros, acabam servindo de base para o dimensionamento de ações que visem o cumprimento da resolução vigente.

Para Wu et al. (2014), é importante obter um levantamento apurado da situação dos RCD para a elaboração de um eficiente plano de gestão e de gerenciamento. Além disso, as taxas de geração de resíduo podem ajudar no fornecimento de informações para o benchmarking da eficácia de diferentes práticas de gestão.

A análise qualitativa visa evidenciar a caracterização física dos resíduos e a percepção da dinâmica da sua gestão, bem como o seu desempenho. Para Godoy (1995), essa análise também objetiva compreender o fenômeno que está sendo estudado, considerando que todos os dados da realidade são importantes e devem ser examinados. 0 ambiente e as pessoas nele inseridos devem ser olhados de forma conjunta, sem que sejam reduzidos a variáveis, mas observados como um todo.

As vantagens econômicas da reciclagem em substituição às deposições irregulares de RCD podem ser notadas nos custos de limpeza urbana, pelas administrações municipais, devido ao alto custo do descarte irregular, correção da deposição com aterramento e controle de doenças, que custam em média U\$10/m de RCD, contra um custo $25 \%$ menor para a reciclagem. Além disso, a eficiência da reciclagem dos RCD pode ser melhorada caso exista um conjunto de instruções acompanhadas de avanços tecnológicos (Tessaro et al., 2012).

\section{Métodos}

Essa pesquisa pode ser classificada como exploratória, pois se valeu de dados e de documentos disponibilizados para tal fim (Cooper \& Schindler, 2011).

A coleta de materiais e de dados foi realizada na cidade de Belo Horizonte, centro urbano e capital do Estado de Minas Gerais. Segundo dados do IBGE (2017), o município possui território de $331.401 \mathrm{~km}^{2} \mathrm{e}$ sua população é estimada em 2,5 milhões de habitantes, dos quais, de acordo com a CBIC (2016), aproximadamente 205 mil trabalham formalmente no ramo da construção.

\section{Análise da gestão e do gerenciamento dos RCD em Belo Horizonte}

Inicialmente, buscou-se identificar possíveis programas e projetos implantados recentemente pela PBH voltados para a gestão dos resíduos sólidos no município e, especificamente, para os RCD. Em seguida, foi realizada uma pesquisa junto à Superintendência de Limpeza Urbana (SLU), por meio de material disponibilizado por esta autarquia municipal responsável pela elaboração, controle e execução de programas e atividades voltados para a limpeza urbana de Belo Horizonte, a fim de verificar quais são os procedimentos referentes à coleta e à destinação final dos RCD realizadas no município de $\mathrm{BH}$, bem como os agentes envolvidos.

Após a identificação desses agentes - setor público e privado de coleta - foi feita uma visita à SLU com a finalidade de coletar informações estatísticas recentes a respeito das cargas, sua composição, destinação final, tipos de equipamentos utilizados, etc., e esclarecer o papel dos agentes privados na dinâmica de gestão dos resíduos na capital por meio de entrevistas aos funcionários da Divisão de Reciclagem, entre outros.

Foram adotados os Relatórios Anuais de Atividades da Limpeza Urbana (RALU) referentes aos anos de 2006 a 2016 disponibilizados pela SLU. O RALU é uma publicação que reúne, de forma sistemática, as 
principais informações sobre a execução da política pública de manejo de resíduos sólidos urbanos no Município de Belo Horizonte (Belo Horizonte, 2016a). Neles, são compiladas as informações encaminhadas pelas gerências das nove regiões administrativas da cidade e de departamentos internos da autarquia que gerenciam informações relevantes.

Através dos relatórios, foi feito o registro da massa total de RCD e a sua representação dentro do total de resíduos sólidos destinados no município de Belo Horizonte. Em seguida, foram relacionadas as parcelas de RCD direcionadas à aterragem e à reciclagem (reaproveitamento) e suas respectivas correspondências percentuais. Foi observado, também, o comportamento dessas variáveis no período de abrangência dos relatórios, procurando analisar a evolução anual dos dados de RCD e possíveis alterações na metodologia de organização das informações. Pelas entrevistas, foi possível entender a dinâmica temporal da gestão e do gerenciamento dos RCD na cidade de Belo Horizonte, pontuando-se as dificuldades encontradas pela administração direta.

0 conceito "resíduos destinados" refere-se à parcela de resíduos coletados pela SLU, a partir do descarte voluntário da população, e encaminhados ao sistema de triagem e de reciclagem pelas empresas de coleta. Essa classificação procura distinguir o destino dos resíduos em contraste com os conhecidos "lixões", que são os locais em que os resíduos são depositados sem tratamento ou separação, proibidos pela Lei no 12.305 (Brasil, 2010). Assim, pode-se afirmar basicamente que os RCD são direcionados aos aterros sanitários. A expressão também é usada nos relatórios supracitados.

\section{Caracterização quantitativa e qualitativa dos resíduos gerados}

A caracterização qualitativa e quantitativa de amostras de RCD foi realizada a partir dos resíduos da Estação de Reciclagem de Entulho - ERE, localizada na BR 040. Utilizou-se o método de amostragem de acordo com a NBR 10007 (ABNT, 2004a) e adotado como fonte da amostra o montante de resíduos recebidos na ERE provenientes de diferentes Unidades de Recebimento de Pequenos Volumes (URPV) em 1 (um) dia útil. Foram coletadas, no resíduo recém-recebido, cinco amostras, em recipientes plásticos de 18 L cada, para posterior caracterização (Figura 1).

Com o total de amostras representativas da composição dos RCD (90 L), realizaram-se a separação e a classificação dos componentes, a determinação da massa dos resíduos (apresentada posteriormente em kg), a análise gravimétrica e a densidade aparente média dos RCD recém-recebidos pela SLU. Também foram aferidos os valores de massa unitária (NBR NM 45, 2006) (ABNT, 2006) e de massa específica (NBR NM 52, 2003) (ABNT, 2003) dos RCD após o processo de moagem na usina da ERE, no estado em que é comercializado como agregado miúdo (Figuras 2 e 3). Para esses dois últimos ensaios, foi coletada uma amostra de $30 \mathrm{~L}$ nos RCD processados na ERE-BR040. 


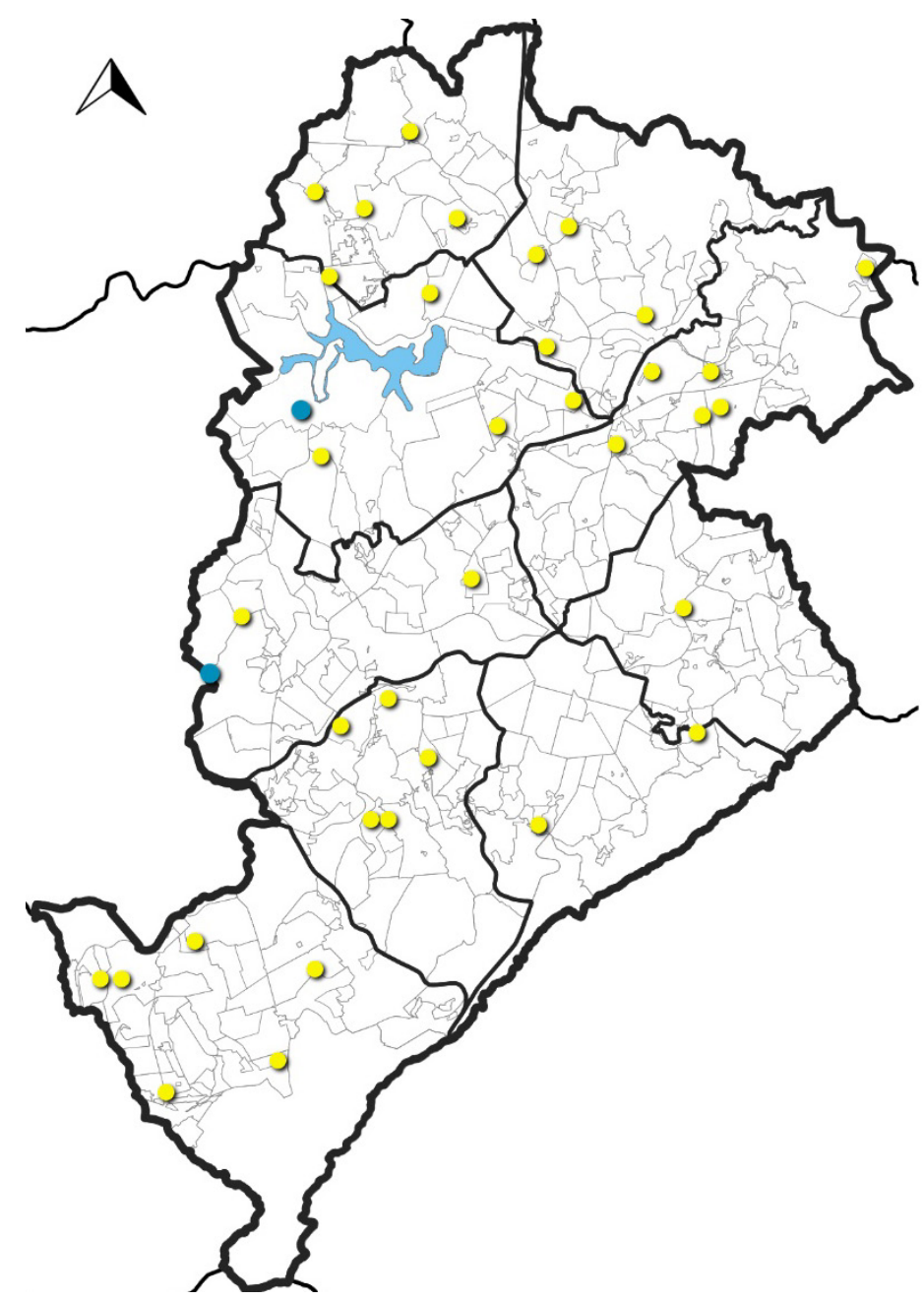

URPVs

ETE

Escala gráfica $(\mathrm{km})$

2.75 .4

Fonte: Google Maps, SLU (PBH).

Figura 1 - URPV e ETEs em Belo Horizonte/MG. Fonte: Belo Horizonte (2016a) (adpatado).

Como parte da pesquisa qualitativa, e também para se ter uma percepção do gerenciamento dos RCD pela SLU, foram coletadas: i) informações referentes ao funcionamento e à dinâmica de triagem de RCD pela SLU, incluindo o fluxograma do processo de operação da usina; ii) dados sobre os tipos de materiais gerados, suas respectivas proporções no montante produzido na estação, valores e demanda do material no mercado da construção civil; e iii) a densidade média dos RCD a fim de comparação com os resultados obtidos. 


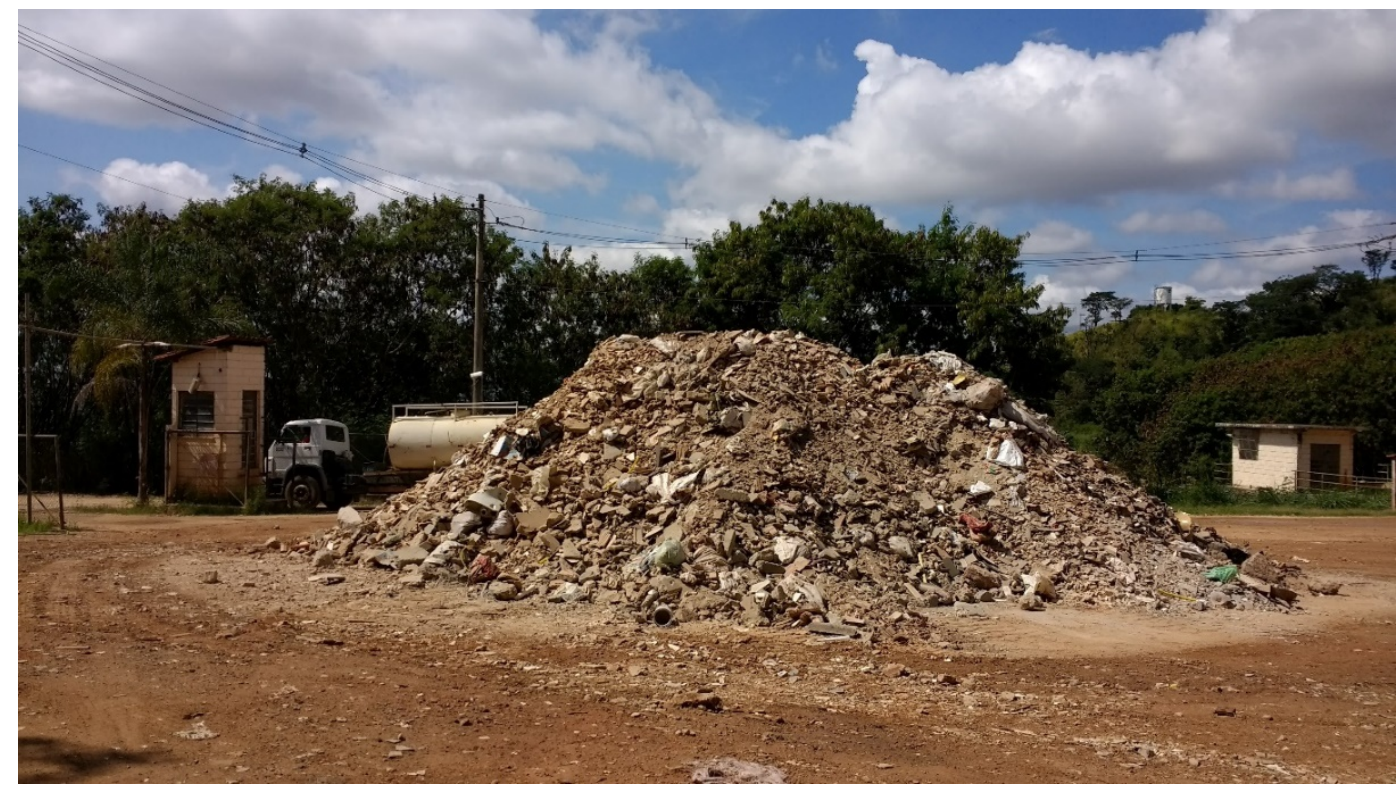

Figura 2 - RCD recebidos na ERE da BR 040. Fonte: Acervo pessoal.

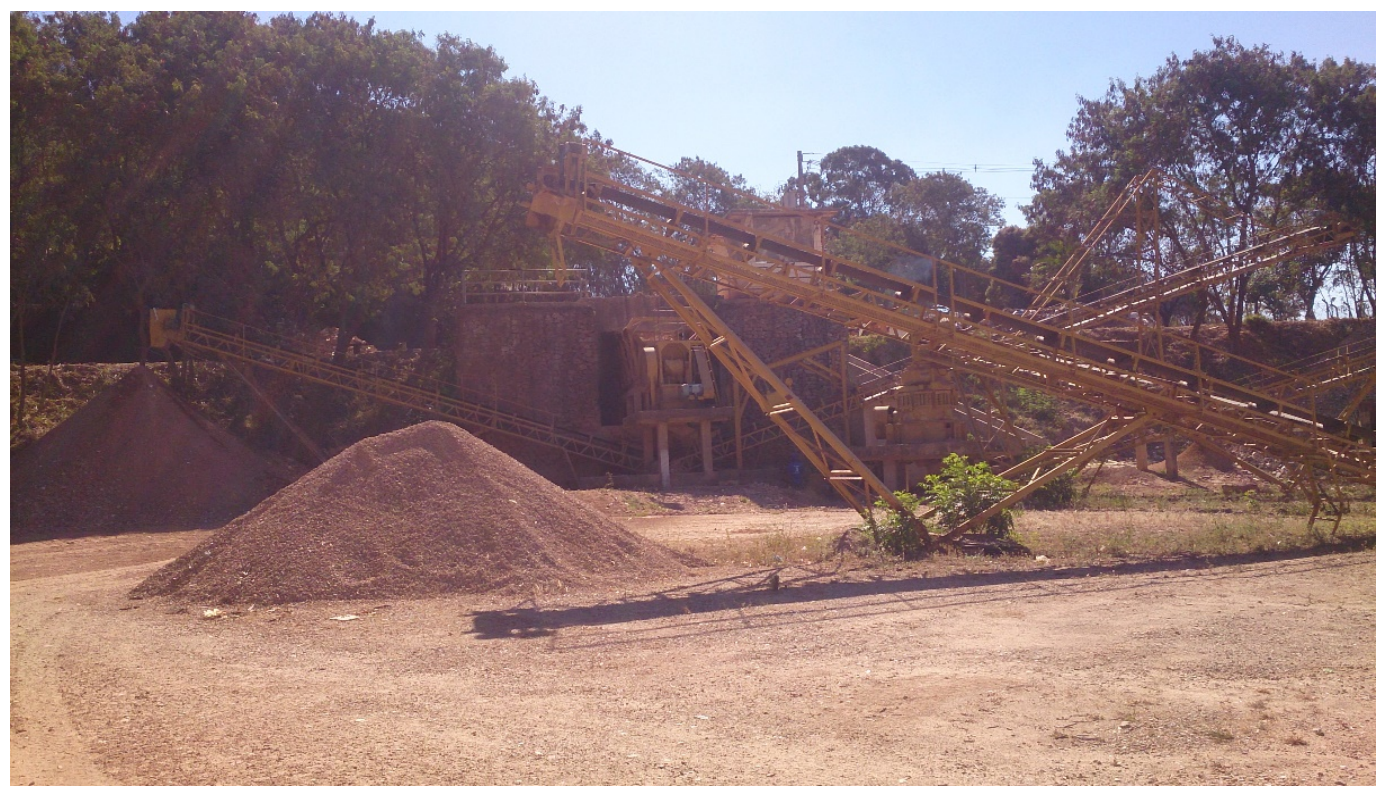

Figura 3 - Processo de moagem dos RCD na usina. Fonte: Acervo pessoal.

Procurou-se, ainda, verificar a existência de deposições clandestinas e analisar o controle por parte do poder público com o intuito de somar o quantitativo de resíduos desses locais ao total registrado no sistema de gerenciamento do município.

\section{Resultados e discussões}

\section{O gerenciamento dos RCD no município de Belo Horizonte}

A cidade de Belo Horizonte se destaca por ter sido pioneira no cenário nacional pela implantação de um sistema de gerenciamento de resíduos sólidos e no processo de reciclagem de RCD. Inicialmente, a gestão 
municipal conseguiu desenvolver uma metodologia para o emprego dos reciclados na própria cidade, reutilizando os RCD para pavimentação de ruas e de estradas e para a fabricação de blocos pré-moldados.

Por conta disso, estima-se que, desde 1996, a Prefeitura de Belo Horizonte (PBH) economizou mais de R\$ 10 milhões de reais com a aplicação de cerca de 1 milhão de toneladas de RCD para a produção de blocos, meios-fios, e pavimentação de obras públicas (Belo Horizonte, 2018b). Todavia, a fabricação de blocos não é mais realizada, o que incentiva novas pesquisas no sentido de apontar a viabilidade técnica e gerencial para implantação de alternativas mais sustentáveis (Resende, 2016).

Vinculada à PBH, a Superintendência de Limpeza Urbana (SLU) atua no município através de atividades de varrição, coleta domiciliar, reciclagem de resíduos, aterro, compostagem, entre outras, e busca realizar o trabalho em consonância com os princípios do desenvolvimento sustentável, referendados na Agenda 21 Brasileira (Brasil, 2006), minimizando os efeitos ambientais negativos decorrentes da geração de resíduos e maximizando os benefícios ambientais, sociais e econômicos para o município. 0 trabalho da autarquia tem como finalidade diminuir os impactos causados pela destinação incorreta de resíduos, que acarretam danos ambientais, sociais e econômicos.

No início dos anos 1990, foi elaborado o Plano de Reciclagem de Resíduos da Construção Civil no município, sendo esse implantado em 1995. O programa foi pioneiro no país e serviu como referência para a elaboração da Resolução no 307 do CONAMA, expandindo a lógica do plano de gestão em nível nacional. A cidade de Belo Horizonte passou a dispor de três Estações de Reciclagem de Entulho (ERE) instaladas nas regiões Noroeste, Oeste e Pampulha. Em 2013, a ERE da região Oeste (bairro Estoril) foi desativada.

Em 2012, a Prefeitura de Belo Horizonte publicou a lei 10.522 (Belo Horizonte, 2012), que instituiu o Sistema de Gestão Sustentável de Resíduos da Construção Civil e de Resíduos Volumosos e o Plano Municipal de Gerenciamento Integrado de Resíduos da Construção Civil e Resíduos Volumosos. Através dessa lei, os geradores de RCD passaram a estar obrigados a elaborar um Plano de Gerenciamento de Resíduos de Construção Civil sendo, também, responsáveis pela gestão dos resíduos.

Em 2014, foi assinado o Termo de Cooperação Técnica entre a SLU e Agência Metropolitana de Belo Horizonte com o objetivo de acompanhar a elaboração do Plano de Gestão Integrada de Resíduos da Região Metropolitana. 0 termo inclui a gestão dos RCD dos municípios da Região Metropolitana de Belo Horizonte e do colar metropolitano.

Atualmente, o sistema de gerenciamento de resíduos da cidade conta com 35 Unidades de Recebimento de Pequenos Volumes (URPV) e duas Estações de Tratamento (ETE), como mostrado na Figura 4. Desde 2015, foram implementadas, também, as Unidades de Entrega Provisória (UEP). A diretriz aplicada pela PBH indica os locais onde as unidades devem ser implantadas, que são pontos com maior incidência de disposição clandestina de RCD. De acordo com a situação, as UEP podem permanecer nos locais tornando-se URPV ou podem ser desativadas (Resende, 2016). 


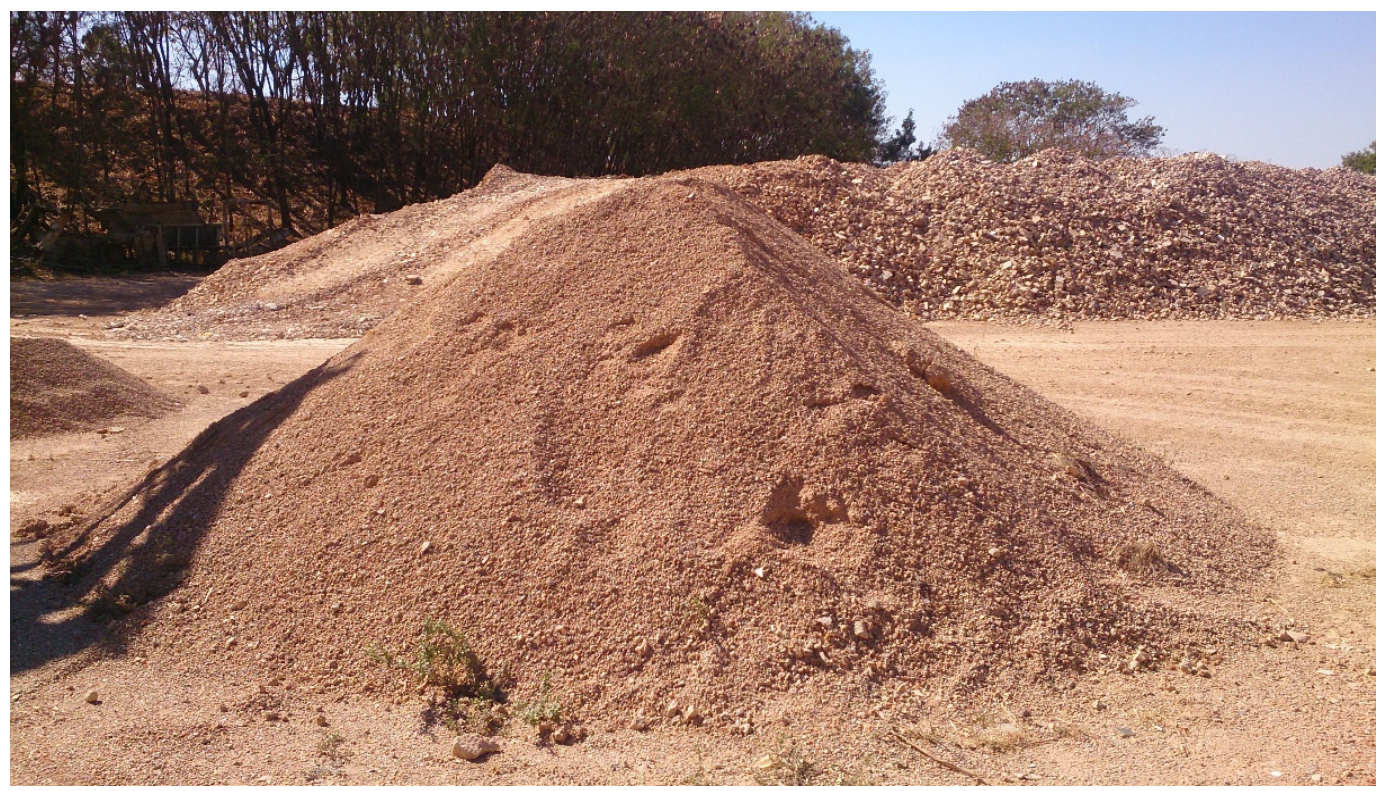

Figura 4 - Pilha de RCD com granulometria compatível com a areia. Fonte: Acervo pessoal.

Em abril de 2017, a PBH lançou o Plano Municipal de Gestão Integrada de Resíduos Sólidos de Belo Horizonte (PMGIRS). O PMGIRS-BH é um instrumento de planejamento estratégico municipal, que contempla as diretrizes e ações para o manejo ambientalmente adequado e sustentável dos resíduos, assim como para a educação ambiental e mobilização social, em um horizonte de 20 anos, sendo assim um Plano que enfatiza a sustentabilidade econômica e ambiental e a inclusão social. 0 plano traz medidas com o fim de otimizar o sistema vigente, visando à educação ambiental de qualidade, controle, comunicação e acompanhamento social, sustentabilidade financeira e ambiental, à modernização e otimização operacional, etc. (Belo Horizonte, 2018b).

Foi concluído um estudo de viabilidade técnica para contratação de sistema informatizado para monitoramento e controle dos Resíduos de Construção e Demolição capaz de monitorar o fluxo desses resíduos e modernizar a análise e aprovação dos Planos de Gerenciamento (Belo Horizonte, 2018a).

\section{A gestão dos RCD em Belo Horizonte}

Os agentes privados de coleta de RCD em Belo Horizonte surgem nesse cenário como locadores de caçambas para a coleta e transporte de resíduos para as estações de reciclagem ou para os aterros disponíveis em Sabará/MG e em Santa Luzia/MG, ambos municípios da Região Metropolitana de Belo Horizonte. Não há controle por parte da SLU da quantidade de resíduos coletados e transportados e da relação das empresas responsáveis por esse serviço.

Na cidade, apresentam-se duas principais classes de geradores de RCD: i) aqueles gerados por obras de maior porte, que segregam os resíduos para reutilização no próprio canteiro ou os disponibilizam para empresas regulares de coleta; e ii) aqueles gerados por pequenas obras, sem nenhum tipo de tratamento ou separação, geralmente descartados em caçambas, mas também lançados irregularmente em vias públicas ou destinados às URPV.

Em 2015, foram coletadas em Belo Horizonte cerca de 612 mil toneladas de RCD, que representaram $42,7 \%$ do total de resíduos destinados na cidade, o que ratifica sua relevância no quantitativo de resíduos gerados na capital, gerando um valor entre 0,24 e 0,26 toneladas de RCD/habitante/ano, se for considerado todo o período analisado.

Esse valor ainda é muito menor do que a média nacional, no valor de 0,50 tonelada de RCD/habitante/ano (Oliveira et al., 2011). Ainda assim, não deve ser utilizado como multiplicador per capita (para fins de cálculo de geração total), pois a quantidade de RCD destinados para reciclagem é 
menor do que os RCD gerados em todas as obras de novas construções, demolições de edificações antigas e obras de infraestrutura. Há muitas perdas e descartes irregulares ao longo de todo o processo. Cabe salientar que os descartes de RCD provenientes de obras de infraestrutura são de grande volume e de longa duração e produzem elevada quantidade de resíduos, mas são frequentemente excluídos da literatura (Wu et al., 2014).

Ainda assim, pela primeira vez em um período de dez anos, foi efetuado o registro dos resíduos encaminhados para três destinos: i) reciclagem; ii) aterragem; e iii) triagem e disposição final. Dessa forma, a massa de RCD, que nos anos anteriores era registrada como direcionada ao aterramento, foi reduzida e identificada de outra forma.

Para a triagem e disposição final, que são resíduos encaminhados para áreas onde há triagem da parcela reciclável e deposição final ou temporária de resíduos inertes (Aterro Sanitário de Maquiné/Santa Luzia), foram destinadas 523 mil toneladas de RCD. Trata-se de alterações na identificação dessa massa que antes era registrada como destinada à aterragem. Entretanto, ainda não há discriminação do quantitativo da parcela efetivamente triada e reaproveitada desses resíduos. Na Tabela 1, pode-se observar os dados relativos aos últimos 3 anos coletados.

Tabela 1 - Total de RCD (2014-2016)

\begin{tabular}{cccccc}
\hline Ano & $\begin{array}{c}\text { Total RCD } \\
\text { Destinados (mil t) }\end{array}$ & $\begin{array}{c}\text { RCD Aterrados } \\
(\text { mil } t)\end{array}$ & $\begin{array}{c}\text { RCD Reciclados } \\
\text { (mil } t)\end{array}$ & $\begin{array}{c}\text { RCD - Triagem e } \\
\text { Disposição Final (mil } t)\end{array}$ & $\begin{array}{c}\text { R RCD } \\
\text { Reciclados (mil } \\
\mathbf{t})\end{array}$ \\
\hline 2014 & 404,7 & 354,9 & 49,8 & 0,0 & 12,31 \\
2015 & 612,6 & 21,6 & 67,9 & 523,0 & 11,08 \\
2016 & 190,5 & 9,5 & 24,4 & 157,0 & 12,83 \\
\hline
\end{tabular}

Fonte: Belo Horizonte (2016a).

Ao mesmo tempo, apesar de o quantitativo de RCD encaminhados à reciclagem ser bastante significativo, sua porção relativa ao total de RCD coletados ainda se mostrou pequena e permanece em torno dos 15\% (em média) em todo o período analisado, com exceção dos anos 2010 e 2011, quando houve um aumento pontual na reciclagem dos RCD (Figura 5). De uma forma geral, os RCD representaram 34,8\% de todos os resíduos aterrados no período analisado (2006-2016), em média, com uma diminuição significativa no ano de 2016. 


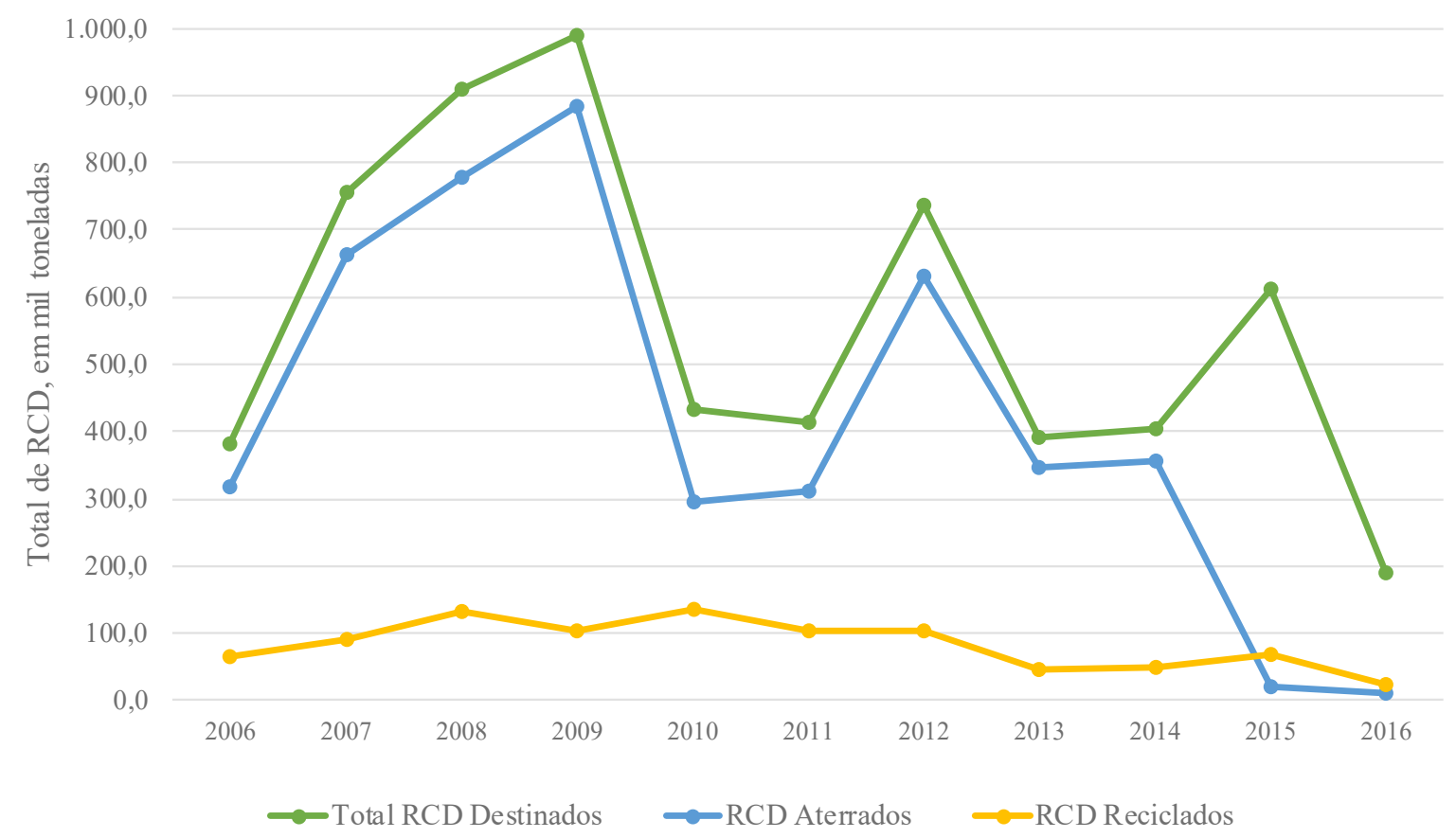

Figura 5 - RCD em Belo Horizonte - período 2006-2016. Fonte: Belo Horizonte (2016a).

Quanto aos depósitos irregulares no município, esses se mostraram de difícil registro e controle, uma vez que a deposição de resíduos ocorre sem previsão de identificação, muitas vezes sendo efetuadas em curto espaço de tempo em lugares muito próximos. Dessa forma, não foi possível distinguir a quantidade de resíduos originária de deposição clandestina.

Alinhada à Política Nacional de Resíduos Sólidos, que possui como um dos princípios "[...] a cooperação entre as diferentes esferas do poder público [...]" (Brasil, 2010), o atual modelo de gestão e gerenciamento dos resíduos sólidos em Belo Horizonte aponta para a adoção de um modelo cooperativo.

O PMGIRS-BH estabeleceu, nesse sentido, várias diretrizes e estratégias de educação ambiental e mobilização social, bem como da integração setorial interna e externa. Reconhece-se, por outro lado, que o envolvimento da população na busca de soluções para as questões relativas à gestão dos resíduos ainda é incipiente e há a proposição de ações de comunicação social que incluam campanhas, propagandas e divulgações em diversas mídias.

Entretanto, nada ou muito pouco ainda pode ser percebido de ações efetivamente aplicadas na cidade ou por meio de veículos de comunicação com vias à sensibilização da população em relação aos resíduos sólidos e, especialmente, aos geradores de RCD, que possam colaborar para a manutenção das condições apontadas pelo próprio estudo em questão.

\section{Caracterização dos resíduos gerados em Belo Horizonte}

Na ERE-BR040, o processo de triagem dos RCD é feito em quatro etapas, que consistem, inicialmente, em separar os RCD do material direcionado ao aterro sanitário. A capacidade atual da ERE-BR040 para recebimento e triagem desses materiais é de $100 \mathrm{~m}^{3} /$ dia. Na portaria da ERE, as caçambas são analisadas para um controle do material recebido (massa e volume do caminhão). 0 volume de outros tipos de resíduos permitido para a entrada nas EREs é de, no máximo, 10\%. Na terceira etapa, os materiais triados como sendo de construções ou demolições são categorizados sobre as classes A e B, conforme a resolução 307 (Brasil, 2002). A quarta etapa consiste na britagem dos materiais para produzir diferentes granulometrias de brita e também de areia (resíduos finos). 
Sobre a análise qualitativa realizada nas amostras coletadas na ERE-BR040 (Tabela 2), pode-se constatar que a composição gravimétrica dos RCD gerados em Belo Horizonte é composta principalmente por resíduos da classe A (blocos, argamassas, concretos, etc.), representados por 95,5\% do total de resíduos gerados, seguidos por resíduos classe B (papel, plástico, vidro e metal), em menor montante. Tal fato demonstra que uma parcela significativa desses resíduos poderia (e deveria) ser reutilizada.

Tabela 2 - Composição gravimétrica das amostras coletadas

\begin{tabular}{cccccccc}
\hline \multirow{2}{*}{$\begin{array}{c}\text { Resíduos } \\
\text { Classe A }\end{array}$} & $\begin{array}{c}\text { Plástico/ } \\
\text { PVC }\end{array}$ & $\begin{array}{c}\text { Papel/ } \\
\text { Papelão }\end{array}$ & Metal & Vidro & Madeira & Gesso & Outros \\
\hline 95,5 & 0,6 & 0,4 & 0,8 & 1,5 & 0,7 & 0,4 & 0,1 \\
\hline
\end{tabular}

Fonte: Dados da pesquisa.

A densidade aparente média dos resíduos coletados para análise qualitativa e quantitativa na SLU ficou em 0,96 ton $/ \mathrm{m}^{3}$, o valor de densidade varia de acordo com o tratamento/moagem dado ao resíduo. As coletas das amostras foram realizadas nos RCD recém-recebidos na usina e antes da triagem que os técnicos fazem, para retirar possíveis contaminantes. Após a triagem, o resíduo é encaminhado para as diferentes etapas de moagem. Ao final do processo de triagem, a densidade aparente média aumenta para 1,60 ton $/ \mathrm{m}^{3}$, aproximadamente (Belo Horizonte, 2016a).

Os resultados das análises físicas atestaram esse valor. A massa unitária dos RCD após a última moagem (resíduo fino) ficou em 1,56 ton $/ \mathrm{m}^{3}$, com um volume de vazios de 1,38\%, compatível com a areia lavada média comercial (dimensão máxima característica de 2,4 $\mathrm{mm}$ ) que possui valor de $1,39 \mathrm{ton} / \mathrm{m}^{3} \mathrm{de}$ massa unitária e $0,11 \%$ de volume de vazios. 0 valor de massa específica dos RCD também se mostrou compatível com o da areia lavada média, respectivamente 2,22 ton $/ \mathrm{m}^{3}$ e 2,49 ton $/ \mathrm{m}^{3}$.

Dos materiais britados produzidos (classe A), uma maior parte a própria PBH pode utilizar em obras rodoviárias e de pavimentação e o restante é disponibilizado para comercialização. Dos materiais gerados na ERE-BR040, em média, 50\% é bica corrida e 50\% rachão, na britagem primária. A precificação é feita conforme a Tabela de Preços Públicos de Serviços Extraordinários de Limpeza, cuja última relação foi publicada em 26 de janeiro de 2016 no Diário Oficial do Município (Belo Horizonte, 2016b) (Tabela 3).

Tabela 3 - Preços Públicos de Serviços Extraordinários de Limpeza da SLU

\begin{tabular}{ccc} 
Produto & Unidade & Valor (RS) \\
\hline Material britado comum (Bica corrida) & $\mathrm{m}^{3}$ & 33,75 \\
Material britado comum (Bica corrida) & $\dagger$ & 21,09 \\
Material britado e peneirado ("brita 0"; "brita 1" e finos) & $\mathrm{m}^{3}$ & 73,39 \\
Material britado e peneirado ("brita 0"; "brita 1" e finos) & $\dagger$ & 45,88 \\
\hline
\end{tabular}

Fonte: SLU (Belo Horizonte, 2016a).

Considerando que a areia média lavada é comercializada no valor de $\mathrm{R} \$ 3,89-5,99$ reais para o pacote de $20 \mathrm{~kg}$ na RMBH (preços cotados ao longo do ano de 2018), seria um valor entre quatro e seis vezes maior no preço da areia em comparação com os RCD finos disponibilizados pela SLU. Somem-se os custos de transporte e, ainda assim, poder-se-ia atestar a viabilidade do uso desse resíduo na construção civil da região. Aos dados técnicos e econômicos apresentados e discutidos por este trabalho, devem-se somar esforços da administração pública para que esses resíduos retornem à cadeia da construção civil, na qual são gerados. 


\section{Conclusões}

O atual panorama do gerenciamento dos resíduos sólidos em Belo Horizonte mostra que o município mantém uma estrutura apropriada para o funcionamento da coleta, do transporte e da triagem de RCD e que tem buscado, nos últimos anos, destinar uma maior parcela dos RCD para triagem e reutilização. Apesar de alguns cortes orçamentários, a PBH segue com a usina da ERE-BR040 como ponto de coleta e processamento de parte dos RCD coletados no município.

Considera-se, também, que o aprimoramento na metodologia de registro das informações pela SLU poderia impactar diretamente a diminuição do volume direcionado aos aterros, bem como a melhor caracterização dos RCD. Essas medidas trariam avanços diretos na gestão e no gerenciamento de resíduos de construção e demolição.

De uma forma geral, os RCD gerados no município apresentam composição predominante do tipo A, o que indica um grande potencial técnico e econômico de reaproveitamento diretamente na construção civil. Entretanto, sugere-se a necessidade de engajamento na aplicação da política de educação ambiental, para que não haja uma elevada incidência de descartes clandestinos, bem como de um melhor gerenciamento das obras de edificações e de reformas, tendo em vista que os dados coletados mostram a manutenção de taxas elevadas na geração de RCD nas atividades de construção civil. Esse tema poderia ser melhor aprofundado em trabalhos futuros, uma vez que não há registro do volume de areia natural usada em Belo Horizonte e do quanto a produção de RCD poderia suprir essa demanda. Essa análise, feita localmente, poderia ser replicada para as grandes cidades brasileiras que despontam nos índices de maiores geradoras de RCD para que a economia circular possa ser efetivamente aplicada na cadeia da construção civil.

\section{Referências}

Agência Nacional de Mineração - ANM. (2010). Anuário Mineral Brasileiro 2010. Recuperado em 22 de dezembro de 2018, de http://www.anm.gov.br/dnpm/publicacoes/serie-estatisticas-e-economia-mineral/anuariomineral/anuario-mineral-brasileiro/anuario-mineral-brasileiro-2010

Associação Brasileira de Empresas de Limpeza Pública e Resíduos Especiais - ABRELPE. (2017). Panorama dos resíduos sólidos no Brasil - 2017. São Paulo: ABRELPE. Recuperado em 21 de dezembro de 2018, de http://abrelpe.org.br/download-panorama-2017/

Associação Brasileira de Normas Técnicas - ABNT. (2003). NBR NM 52: Agregado miúdo - determinação da massa específica e massa específica aparente. Rio de Janeiro: ABNT.

Associação Brasileira de Normas Técnicas - ABNT. (2004a). NBR 10007: Amostragem de resíduos sólidos. Rio de Janeiro: ABNT.

Associação Brasileira de Normas Técnicas - ABNT. (2004b). NBR 15115: Agregados reciclados de resíduos sólidos da construção civil - Execução de camadas de pavimentação - Procedimentos. Rio de Janeiro: ABNT.

Associação Brasileira de Normas Técnicas - ABNT. (2004c). NBR 15116: Agregados reciclados de resíduos sólidos da construção civil - Utilização em pavimentação e preparo de concreto sem função estrutural - Requisitos. Rio de Janeiro: ABNT.

Associação Brasileira de Normas Técnicas - ABNT. (2004d). NBR 10004: Resíduos sólidos - Classificação. Rio de Janeiro: ABNT.

Associação Brasileira de Normas Técnicas - ABNT. (2006). NBR NM 45: Agregados - determinação de massa unitária e volume de vazios. Rio de Janeiro: ABNT.

Baptista, J. V., Jr., \& Romanel, C. (2013). Sustentabilidade na indústria da construção: uma logística para reciclagem dos resíduos de pequenas obras. Urbe. Revista Brasileira de Gestão Urbana, 5(2), 27-37.

http://dx.doi.org/10.7213/urbe.05.002.SE02. 
Belo Horizonte. Prefeitura Municipal. (2012). Lei № 10.522, de 24 de agosto de 2012. Belo Horizonte: Diário Oficial do Município - DOM. Recuperado em 13 de janeiro de 2018, de http://portal6.pbh.gov.br/dom/iniciaEdicao.do?method=DetalheArtigo\&pk=1086436

Belo Horizonte. Prefeitura Municipal. (2015). Coleta, destinação e tratamento de resíduos sólidos. Belo Horizonte: Prefeitura Municipal. Recuperado em 15 de setembro de 2017, de https://bhmetaseresultados.pbh.gov.br/content/coleta-destina\%C3\%A7\%C3\% A3o-e-tratamento-deres\%C3\%ADduos-s\%C3\%B3lidos

Belo Horizonte. Prefeitura Municipal. Superintendência de Limpeza Urbana - SLU. (2016a). Relatório anual de atividades da limpeza urbana 2006-2016 [Documento cedido]. Belo Horizonte: Prefeitura Municipal.

Belo Horizonte. Prefeitura Municipal. (2016b). Decreto no 16.217, de 26 de janeiro de 2016. Belo Horizonte: Diário Oficial do Município - DOM. Recuperado em 26 de dezembro de 2018, de http://portal6.pbh.gov.br/dom/iniciaEdicao.do?method=DetalheArtigo\&pk= 1157142

Belo Horizonte. Prefeitura Municipal. (2018a). Plano Municipal de Gestão Integrada dos Resíduos Sólidos de Belo Horizonte. Belo Horizonte: Prefeitura Municipal. Recuperado em 12 de maio de 2018, de https://prefeitura.pbh.gov.br /sites/default/files/estrutura-degoverno/slu/2018/documentos/versao_final_pmgirs-h_mma.pdf

Belo Horizonte. Prefeitura Municipal. Superintendência de Limpeza Urbana - SLU. (2018b). Estatísticas. Recuperado em 10 de março de 2018, de https://prefeitura.pbh.gov.br/ slu/informacoes/estatisticas

Bernardes, A., Thomé, A., Prietto, P. D. M., \& Abreu, A. G. (2008). Quantificação e classificação dos resíduos da construção e demolição coletados no município de Passo Fundo, RS. Ambiente Construído, 8(3), 65-76.

Brasil. Conselho Nacional do Meio Ambiente - CONAMA. (2002, 17 de julho). Resolução $n^{\circ} 307$, de 5 de julho de 2002. Estabelece diretrizes, critérios e procedimentos para a gestão dos resíduos da construção civil. Brasília: Diário Oficial da União. Recuperado em 24 de setembro de 2017, de http://www.mma.gov.br/estruturas/a3p/_arquivos/36_09102008030504.pdf

Brasil. Ministério do Meio Ambiente - MMA. (2006). Agenda 21 brasileira. Brasília: MMA. Recuperado em 22 de novembro de 2017, de http://www.mma.gov.br/responsabilidade-socioambiental/agenda-21/agenda-21brasileira

Brasil. (2010). Lei $n^{\circ}$ 12.305, de 2 de agosto de 2010. Institui a Política Nacional de Resíduos Sólidos; altera a Lei no 9.605, de 12 de fevereiro de 1998; e dá outras providências. Brasília: Diário Oficial da União. Recuperado em 24 de setembro de 2017, de http://www.planalto.gov.br/ccivil_03/_ato2007-2010/2010/lei/112305.htm

Brasil. Ministério do Meio Ambiente - MMA. (2011, 25 de maio). Resolução no 431, de 24 de maio de 2011. Altera o art. 3 o da Resolução no 307, de 5 de julho de 2002, do Conselho Nacional do Meio Ambiente CONAMA, estabelecendo nova classificação para o gesso. Brasília: Diário Oficial da União. Recuperado em 17 de setembro de 2017, de http://www.mma.gov.br /port/conama/legiabre.cfm?codlegi=649

Brasileiro, L. L., \& Matos, J. M. E. (2015). Revisão bibliográfica: reutilização de resíduos da construção e demolição na indústria da construção civil. Cerâmica, 61(358), 178-189. http://dx.doi.org/10.1590/036669132015613581860.

Câmara Brasileira da Indústria da Construção - CBIC. (2016). Pesquisa mensal de emprego - IBGE. Recuperado em 24 de setembro de 2017, de http://www.cbicdados.com.br/media/anexos/tabela_03.C.04_13.xlsx

Cooper, D. R., \& Schindler, P. S. (2011). Métodos de pesquisa em administração (10. ed.). Porto Alegre: Bookman.

Duran, X., Lenihan, H., \& O’Regan, B. (2006). A model for assessing the economic viability of construction and demolition waste recycling - the case of Ireland. Resources, Conservation and Recycling, 46(3), 302-320. http://dx.doi.org/10.1016/j.resconrec.2005.08.003.

Godoy, A. (1995). Introdução à pesquisa qualitativa e suas possibilidades. Revista de Administração de Empresas., 35(2), 57-63. http://dx.doi.org/10.1590/S0034-75901995000200008. 
Instituto Brasileiro De Administração Municipal - IBAM. (2001). Gestão integrada de resíduos sólidos: manual gerenciamento integrado de resíduos sólidos. Rio de Janeiro: IBAM. Coordenação técnica: Victor Zular Zveibil.

Instituto Brasileiro de Geografia e Estatística - IBGE. (2017). Estimativas de população. Rio de Janeiro: IBGE. Recuperado em 24 de setembro de 2017, de http://www.ibge.gov.br/ home/estatistica/populacao/estimativa2015/default.shtm

Monteiro, C., Karpinski, J. A., Kuhl, M. R., \& Morozini, J. F.. (2017). A gestão municipal de resíduos sólidos e as ações de sustentabilidade: um estudo realizado em um município do centro oeste do Paraná. Urbe. Revista Brasileira de Gestão Urbana, 9(1), 139-154. http://dx.doi.org/10.1590/2175-3369.009.001.ao010.

Oliveira, M. E. D., Sales, R. J. M., Oliveira, L. A. S., \& Cabral, A. E. B. (2011). Diagnóstico da geração e da composição dos RCD de Fortaleza/CE. Revista de Engenharia Sanitária e Ambiental, 16(3), 219-224. http://dx.doi.org/10.1590/S1413-41522011000300003.

Resende, L. H. S. (2016). Análise da gestão de resíduos sólidos de construção civil de Belo Horizonte (MG) a partir da percepção dos atores envolvidos [Dissertação de mestrado] Belo Horizonte: Programa de Pós-graduação em Saneamento, Meio Ambiente e Recursos Hídricos, Universidade Federal de Minas Gerais.

Rodríguez, G., Medina, C., Alegre, F. J., Asensio, E., \& Sánchez de Rojas, M. I. (2015). Assessment of construction and demolition waste plant management in Spain: in pursuit of sustainability and eco-efficiency. Journal of Cleaner Production, 90, 16-24. http://dx.doi.org/10.1016/j.jclepro.2014.11.067.

Scremin, L. B., Castilhos, A. B., Jr., \& Rocha, J. C. (2014). Sistema de apoio ao gerenciamento de resíduos de construção e demolição para municípios de pequeno porte. Revista de Engenharia Sanitária e Ambiental, 19(2), 203-206. http://dx.doi.org/10.1590/S1413-41522014000200011.

Tam, V. W. Y., Soomro, M., \& Evangelista, A. J. (2018). A review of recycled aggregate in concrete applications (2000-2017). Construction \& Building Materials, 172, 272-292.

http://dx.doi.org/10.1016/j.conbuildmat.2018.03.240.

Tessaro, A. B., Sá, J. S., \& Scremin, L. B. (2012). Quantificação e classificação dos resíduos procedentes da construção civil e demolição no município de Pelotas, RS. Ambiente Construído, 12(2), 121-130. http://dx.doi.org/10.1590/S1678-86212012000200008.

Wu, Z., Yu, A. T. W., Shen, L., \& Liu, G. (2014). Quantifying construction and demolition waste: an analytical review. Waste Management (New York, N.Y.), 34(9), 1683-1692. http://dx.doi.org/10.1016/j.wasman.2014.05.010. PMid:24970618.

Yeheyis, M., Hewage, K., Alam, M. S., Eskicioglu, C., \& Sadiq, R. (2013). An overview of construction and demolition waste management in Canada: a lifecycle analysis approach to sustainability. Clean Technologies and Environmental Policy, 15(1), 81-91. http://dx.doi.org/10.1007/s10098-012-0481-6.

Editor: Rodrigo Firmino.

Recebido: Dez. 27, 2018

Aprovado: Fev. 4, 2019 